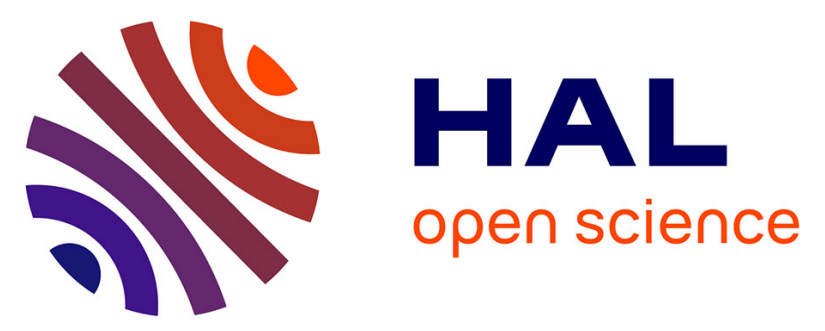

\title{
Transcarotid versus transfemoral access in patients undergoing transcatheter aortic valve replacement with complex aortofemoral anatomy
}

Florence Leclercq, Romuald Choteau, Guillaume Cayla, Chloé Chamard, Youcef Lounes, Benoit Lattuca, Jean-Christophe Macia, Delphine Delseny, Mariama Akodad, Thomas Gandet

\section{To cite this version:}

Florence Leclercq, Romuald Choteau, Guillaume Cayla, Chloé Chamard, Youcef Lounes, et al.. Transcarotid versus transfemoral access in patients undergoing transcatheter aortic valve replacement with complex aortofemoral anatomy. Catheterization and Cardiovascular Interventions, 2020, 10.1002/ccd.29438 . hal-03177347

\section{HAL Id: hal-03177347 \\ https://hal.umontpellier.fr/hal-03177347}

Submitted on 16 Nov 2021

HAL is a multi-disciplinary open access archive for the deposit and dissemination of scientific research documents, whether they are published or not. The documents may come from teaching and research institutions in France or abroad, or from public or private research centers.
L'archive ouverte pluridisciplinaire HAL, est destinée au dépôt et à la diffusion de documents scientifiques de niveau recherche, publiés ou non, émanant des établissements d'enseignement et de recherche français ou étrangers, des laboratoires publics ou privés. 


\title{
Transcarotid versus transfemoral access in patients undergoing transcatheter aortic valve replacement with complex aortofemoral anatomy
}

\author{
Florence Leclercq MD, $\mathrm{PhD}^{1} \quad$ Romuald Choteau $\mathrm{MD}^{1} \quad$ | Guillaume Cayla MD, $\mathrm{PhD}^{2} \quad$ | \\ Chloé Chamard MD ${ }^{3}$ | Youcef Lounes MD $^{4}$ | Benoit Lattuca MD, PhD ${ }^{2}$ | \\ Jean-Christophe Macia MD ${ }^{1}$ | Delphine Delseny MD $^{1}$ | \\ Mariama Akodad MD, PhD ${ }^{1,5}$ | Thomas Gandet MD
}

\footnotetext{
${ }^{1}$ Department of Cardiology, University Hospital of Montpellier, Montpellier, France

${ }^{2}$ Department of Cardiology, University

Hospital of Nimes, Nimes, France

${ }^{3}$ Department of Ophtalmology, University Hospital of Montpellier, Montpellier, France

${ }^{4}$ Department of Thoracic and Vascular Surgery, University Hospital of Montpellier, Montpellier, France

${ }^{5}$ PhyMedExp, University of Montpellier, Montpellier, France

${ }^{6}$ Department of Cardiovascular Surgery, University Hospital of Montpellier,

Montpellier, France

Correspondence

Thomas Gandet, Department of Cardiovascular Surgery, Hôpital Arnaud de Villeneuve, 371 Avenue du Doyen Gaston Giraud, 34295 Montpellier, France.

Email: thomas.gandet@gmail.com
}

\begin{abstract}
Aims: While major vascular complications (MVC) remains an issue after Transfemoral (TF) transcatheter aortic valve replacement (TAVR), we compared outcomes in TF versus transcarotid (TC) approaches in patients with complex vascular anatomy.

Methods and results: Among patients undergoing TAVR in our center between 2015 and 2018, we evaluated patients with complex vascular anatomy defined on CT scan as: (a) iliofemoral diameter between 5.5 and $6 \mathrm{~mm}$ or $<6.5 \mathrm{~mm}$ with severe calcifications or tortuosity AND/OR (b) abdominal aorta pathology. The primary endpoint included access failure, mortality, MVC, major bleeding and stroke at 1-month. Among 483 patients, 131 (31.2\%) with complex vascular anatomy underwent TF ( $n=51 ; 39.2 \%$ ) or TC ( $n=80 ; 60.8 \%$ ) TAVR. The mean age was $81.7 \pm 6.9$. TC group had higher STS score $(p=.01)$, higher incidence of coronary artery disease $(p=.04)$ and lower left ventricular ejection fraction $(p<.001)$. In TC group, primary endpoint occurred twice less without reaching significance compared to TF group ( $n=8 ; 10.0 \%$ vs. $n=10 ; 19.6 \%$ respectively; $p=.1$ ). Incidence of MVC was higher in TF group (11.8 vs. $1.3 \%$ in the TC group; $p=.01$ ) with similar incidence of stroke between groups $(p=.8)$.

Conclusions: Despite higher patient risk profile, TC approach in complex aortofemoral anatomy provides similar favorable outcomes with less MVC compared to TF approach.
\end{abstract}

\section{KEYWORDS}

complex anatomy, TAVR, transcarotid, transfemoral, vascular complication
Abbreviations: ICU, intensive care unit; LVEF, left ventricular ejection fraction; MSCT, multislice computerized tomographic angiography; STS, society of thoracic surgeons; TAVR, transcatheter aortic valve replacement; TC, transcarotid; TF, transfemoral; VARC-2, valve academic research consortium-2; MVC, major vascular complication.

\section{1 | INTRODUCTION}

European guidelines recommend transfemoral (TF) approach as the first line access for transcatheter aortic valve replacement (TAVR) 
when vessels anatomy is favorable. ${ }^{1}$ However, some anatomic challenges as low vessel diameter, vascular tortuosity, calcifications or aortoiliac vascular pathology may increase the risk of procedural complications and failure leading to consider alternative access sites. $^{2-6}$ Transaortic and transapical accesses are invasive hybrid approaches and are associated with less favorable results than TF approach. $^{4-6}$ Subclavian access may be difficult in case of obesity, small artery diameter or important calcifications, and may be avoided in case of patent mammary artery bypass. ${ }^{7}$ More recently, the transcarotid (TC) approach initially developed by Modine et al. in $2010^{8}$ showed encouraging results in terms of feasibility and safety. ${ }^{9,10}$

The purpose of this study was to compare outcomes between TF and TC access in patients undergoing TAVR when ilio-femoral or aortic anatomy is possible but complex regarding vessel diameters, calcifications and/or tortuosity.

\section{2 | METHODS}

\section{1 | Study design and patients}

Among patients undergoing TAVR in Montpellier University Hospital between 2015 and 2018, we included all patients undergoing TF or TC procedure with complex ilio-femoral and/or complex aortic anatomy according to multislice computerized tomographic (MSCT) analysis. All patients provided written informed consent. The protocol was approved by the local ethics committee (Comité de Protection des Personnes Sud Méditerranée, Montpellier, France), the institutional regulatory authorities (Institut Review Board [IRB]) of Montpellier University Hospital and was conducted according to the principals of the Declaration of Helsinki.

\section{2 | MSCT analysis}

Before the procedure, a MSCT analysis of the aortic valve, the entire aorta, iliofemoral and supra-aortic vessels using vascular windows settings was performed in all patients (General Electric LightSpeed VCT). After 3-dimensions reconstruction of the iliofemoral vessels and the aorta using OsiriX DICOM viewer (Pixmeo company, Geneva, Swiss), diameter, calcifications and tortuosity were determined by three different physicians, including a radiologist, an interventional cardiologist and a cardiac surgeon. Minimal luminal diameter measurements were performed perpendicular to the vessel axis. Evaluation of tortuosity was based on the most severe angulation of the iliofemoral system or abdominal aorta in anterior/posterior or medial/lateral directions. Vessels calcifications were graded as none, mild, moderate or severe. ${ }^{11}$ Anatomy and calcifications of the carotid vessels were also evaluated according to same rules. Common carotid arteries diameter and calcifications were systematically analyzed using vascular Doppler ultrasonography.

\subsection{Definition of complex femoral and aortic anatomy}

TF access was considered as favorable when iliofemoral artery diameter was $>6.5 \mathrm{~mm}$, and complex when ilio femoral artery diameter was between 5.5 and $6 \mathrm{~mm}$ or between 6 and $6.5 \mathrm{~mm}$ AND associated with severe calcifications and/or severe tortuosity. According to guidelines of the Society of Vascular surgery, severe iliofemoral tortuosity was defined by more than one angulation $<90^{\circ}$ and severe calcification when more than $50 \%$ of the vessel segment length calcified or heavily circumferential calcified. ${ }^{11} \mathrm{Com}$ plex aortic anatomy included abdominal aortic aneurysm, chronic aortic dissection, tortuosity $>45^{\circ}$ or penetrating aortic ulcer (Figure 1). TF approach was contra-indicated in case of ilio femoral artery $<5.5 \mathrm{~mm}$, severe stenosis, circumferential aortic thrombus or shaggy aorta. Only carotid diameter $\geq 5.5 \mathrm{~mm}$ with none or mild calcifications was considered as acceptable for TC TAVR procedure. Severe calcifications in the aortic arch, controlateral carotid stenosis or occlusion contra-indicated TC access.

\section{4 | TAVR procedure}

Access site was left to the operators' discretion. For TF access, a surgical "preclose technique" or a percutaneous access using double Proglide (Abott vascular) technique was used depending on the operator's choice. ${ }^{12}$ For TC access, a surgical approach was systematically performed. The common carotid was approached between the two chiefs of the sternocleido-mastoïdian muscle and the omohyoid strap muscle was cut. The carotid artery was carefully dissected to avoid injury of the vagus nerve. One vessel-loop was set up on the carotid which was punctured before the insertion of a $6 \mathrm{~F}$ introducer. The sheath (Ascendra certitude delivery, commander delivery and EnVeo Medtronic according to the selected valve) was introduced via a counter-incision made just above the neck incision to provide more stability to the procedure. We paid particular attention to reduce the duration of carotid occlusion during the procedure. Predilatation when indicated was performed through a small diameter sheath. A fast surgical closure was chosen using a running suture. A 6F catheter secondary arterial access was inserted through the radial or femoral artery and another 6F catheter was positioned in the femoral vein for right ventricular pacing for balloon-expandable valve implantation. All patients received $0.5 \mathrm{mg} / \mathrm{kg}$ of heparin at the time of introducing the sheath. An association of clopidogrel $75 \mathrm{mg}$ and aspirin $75 \mathrm{mg}$ was prescribed for all patients after TAVR, except those with indication for long term anticoagulant therapy, in whom only aspirin $75 \mathrm{mg}$ was added.

\section{5 | Study end-points}

The primary endpoint was a combined endpoint of safety and efficacy at 1-month including access failure, all-cause mortality, major vascular complications (MVC), major bleeding and stroke according to Valve academic research consortium-2 (VARC-2) criteria. $^{13}$ The TC or TF 

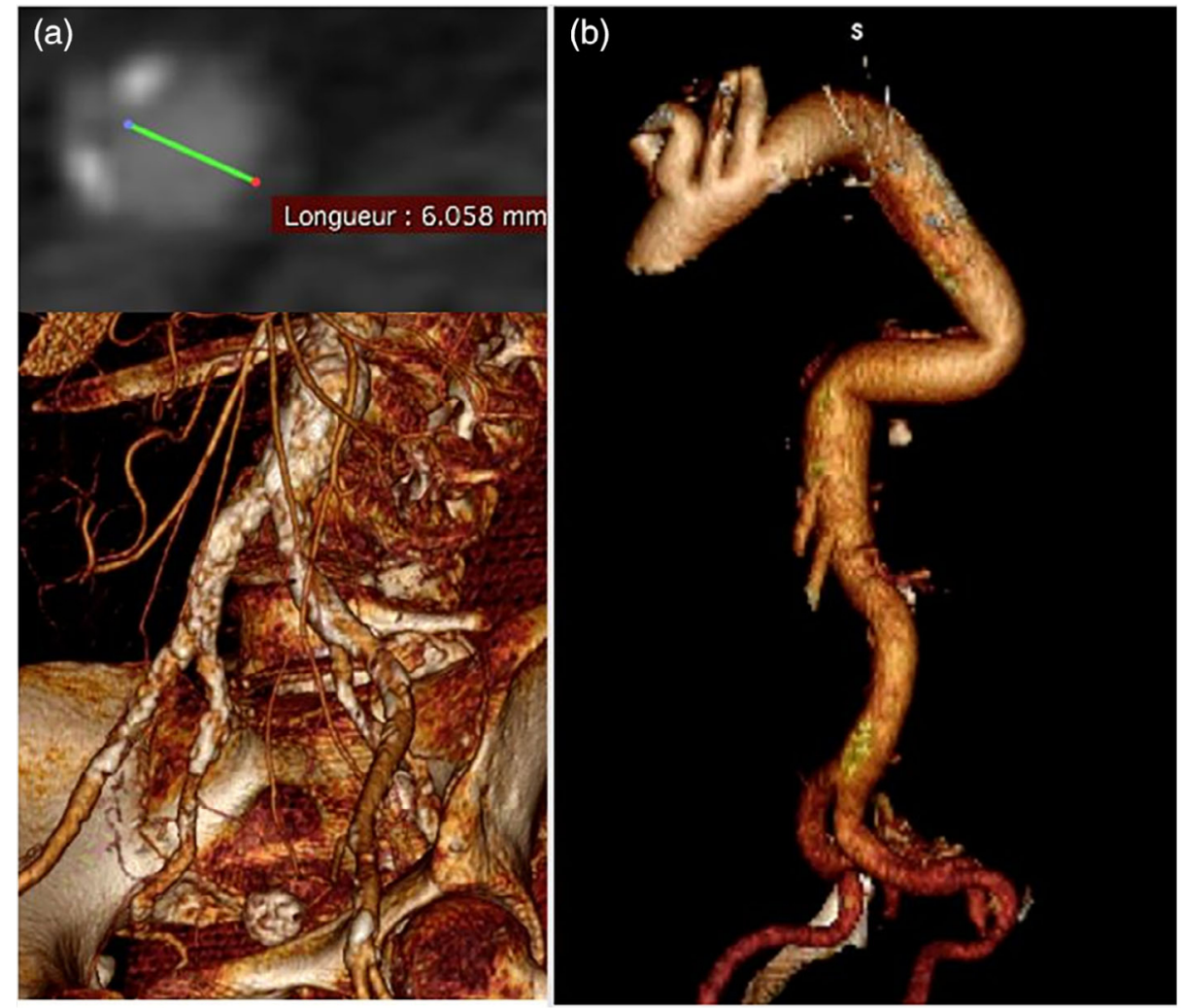

FIGURE 1 A: complex femoral anatomy B: Aortic tortuosity [Color figure can be viewed at wileyonlinelibrary.com] access failure was defined by the need of a surgical conversion by sternotomy or conversion for another access. Each patient with suspected stroke had an emergency brain magnetic resonance imaging (MRI) or an injected brain scanner in case of contraindication to MRI. The diagnosis was confirmed by a neurologist.

Secondary endpoints included major outcomes at 1-month follow-up including more than mild aortic regurgitation, pacemaker implantation, new hospitalization for cardiac causes. Evaluation of procedural factors included procedure length, radiation dose, contrast amount, post dilatation rate, and hospital length of stay.

Data on baseline characteristics, procedural results and inhospital outcomes were collected from medical records. The 1-month outcomes were collected through the usual follow-up consultations with the cardiologist or by phone interview with the patient.

\subsection{Statistical consideration}

Characteristics of the study participants were described with mean (SD) for continuous variables and number (\%) for categorical variables. We used the Student $\mathrm{t}$ test and Chi-square test to compare groups. An univariate logistic regression was performed to assess the risk of complications. The combined endpoint was verified if at least one of the major endpoints (access failure, all-cause mortality, MVC, major bleeding and stroke) occurred. Statistical significance was set at $p<.05$. SAS Enterprise Guide 7.1 was used for data analysis.

\section{\begin{tabular}{l|l}
3 & RESULTS
\end{tabular}}

\section{1 | Study population}

Among a cohort of 483 patients included within the study period, 131 (31.2\%) patients with complex access vascular anatomy underwent TF $(n=51(39.2 \%))$ or TC $(n=80(60.8 \%))$ TAVR (Figure 2). Baseline characteristics of the population are presented in Table 1. Patients from TC group were at higher risk profile. Women were more frequently encountered in TF group $(p<.001)$. Aortic complex anatomy was more frequent in TC group $(p=.03)$. Detailed characteristics of vascular complex anatomy in both groups are depicted Table 2.

\section{2 | Procedural characteristics}

In the TF group, the procedure was performed by the left side in 31 patients (60.8\%), and a percutaneous technique was used in 31 patients $(60.8 \%)$. In the TC group, the main access was the left carotid ( $n=61(76 \%))$. A balloon expandable valve was used in 93 patients (71\%) without significant difference between the two groups. Pre and post dilatation rates did not differ between the TC and the TF patients. No patient required a second valve implantation or a conversion by sternotomy. Procedural characteristics are presented in Table 3. 
FIGURE 2 Study flow chart [Color figure can be viewed at wileyonlinelibrary.com]
483 patients underwent TAVR February 2015 to February 2018

332 favourable or contra-indicated TF approach $(68.8 \%)$

151 aortic/ iliofemoral complex anatomy $(31.2 \%)$

131 aortic/ iliofemoral complex anatomy included $(27.1 \%)$
20 patients $(4.1 \%)$ excluded for non TF or TC access:

2 subclavian

5 transapical

13 transaortic

TAB LE 1 Baseline characteristics of the population

\begin{tabular}{|c|c|c|c|c|}
\hline & Total population $(n=131)$ & TF access $(n=51)$ & TC access $(n=80)$ & $p$ \\
\hline Age, mean \pm SD (years) & $81.7 \pm 6.9$ & $81.8 \pm 6.3$ & $81.6 \pm 7.5$ & .4 \\
\hline Male gender, $n(\%)$ & $72(54.9)$ & $17(33.3)$ & $55(68.8)$ & $<.001$ \\
\hline $\mathrm{BMI} \mathrm{kg} / \mathrm{m}^{2}$, mean $\pm \mathrm{SD}$ & $26.2 \pm 6.2$ & $25.9 \pm 4.9$ & $26.4 \pm 7.4$ & .8 \\
\hline NYHA class $\geq \mathrm{III}, n$ (\%) & $85(64.9)$ & $32(62.7)$ & $53(66.3)$ & .5 \\
\hline Previous PCI, $n$ (\%) & $59(45.0)$ & $17(33.3)$ & $42(52.5)$ & .05 \\
\hline Previous CABG, $n(\%)$ & $18(13.7)$ & $5(9.8)$ & $13(16.3)$ & .3 \\
\hline Cardiac valve surgery, $n(\%)$ & $10(7.6)$ & $5(9.8)$ & $5(6.3)$ & .5 \\
\hline Pacemaker, n (\%) & $19(14.5)$ & $5(9.8)$ & $14(17.5)$ & .2 \\
\hline Diabetes mellitus $n$ (\%) & $50(38.5)$ & $21(42)$ & $29(36.3)$ & .6 \\
\hline Stroke, $n$ (\%) & $16(12.2)$ & $6(11.8)$ & $10(12.5)$ & 1 \\
\hline Respiratory failure, $n(\%)$ & $41(31.3)$ & $15(29.4)$ & $26(32.5)$ & .8 \\
\hline Atrial fibrillation, $n(\%)$ & $49(37.4)$ & $19(37.3)$ & $27(33.8)$ & .7 \\
\hline Oral anticoagulant, $n(\%)$ & $44(33.6)$ & $15(29.4)$ & $29(36.3)$ & .6 \\
\hline LVEF, mean \pm SD & $53.4 \pm 10.2$ & $57.9 \pm 9.1$ & $48.9 \pm 11.2$ & $<.001$ \\
\hline Mean aortic gradient, mean \pm SD & $48.8 \pm 14.4$ & $53 \pm 14.4$ & $44.6 \pm 13.4$ & .01 \\
\hline STS score, mean \pm SD & $5.9 \pm 4.0$ & $4.5 \pm 2.5$ & $7.3 \pm 5.4$ & .01 \\
\hline Euroscore 2 , mean $\pm S D$ & $6.7 \pm 6$ & $5.5 \pm 3.4$ & $7.8 \pm 8.6$ & .09 \\
\hline
\end{tabular}

Abbreviations: BMI, body mass index; CABG, coronary artery bypass graft; LVEF, left ventricular ejection fraction; NYHA, New York association functional classification; PCI, percutaneous coronary intervention; STS, society of Thoracic Surgeons; TC, transcarotid; TF, complex transfemoral.

\section{3 | Primary endpoint}

In TC group, primary endpoint occurred twice less without reaching significance, compared to TF group ( $n=8(10.0 \%)$ vs. $n=10(19.6 \%)$ respectively); OR (95\% confidence interval) $=0.5(0.2-1.3), p=.1$
(Table 4, Figure 3). A conversion from TF to TC access was necessary in one patient $(2.0 \%)$ in the TF group due to crossing failure of calcified iliac artery ( $6 \mathrm{~mm}$ minimal diameter). At 1-month follow-up, two patients died in the TC group related to septic shock $(n=1,1.3 \%)$ and heart failure $(n=1,1.3 \%)$ versus one patient $(1.9 \%)$ in the TF group 


\begin{tabular}{llll} 
& TF access $n=51$ & TC access $n=80$ & $p$ value \\
Complex femoral access (5.5-6.5 mm) & $48(94.1)$ & $68(85.0)$ & .1 \\
Iliofemoral diameter 5.5-6 mm & $24(50.0)$ & $35(51.5)$ & .7 \\
Iliofemoral diameter 6-6.5 mm AND: & $24(50.0)$ & $33(48.5)$ & .5 \\
Severe tortuosity & $16(66.7)$ & $26(78.8)$ & .8 \\
Severe calcifications & $17(70.8)$ & $31(93.4)$ & .5 \\
Complex aortic access & $6(11.8)$ & $22(27.5)$ & .03 \\
Aneurysm & $2(33.3)$ & $12(54.5)$ & \\
Dissection & $1(16.7)$ & $3(13.6)$ & \\
Penetrating ulcer & $2(33.3)$ & $5(22.7)$ & \\
Tortuosity & $2(33.3)$ & $2(9.1)$ & .2 \\
Complex femoral and aortic access & $4(7.8)$ & $12(1.0)$ & \\
\hline
\end{tabular}

TABLE 2 characteristics of the complex ilio-femoral vascular access in the two study groups

Note: Values are expressed as proportion $n(\%)$.

Abbreviations: TC, transcarotid; TF, complex transfemoral.

TABLE 3 Procedural characteristics

\begin{tabular}{|c|c|c|c|c|}
\hline & Total $(n=131)$ & $\operatorname{TF}(n=51)$ & $\mathrm{TC}(n=80)$ & $p$ \\
\hline General anesthesia, $n(\%)$ & $129(98)$ & $50(98.0)$ & $79(98.7)$ & 1 \\
\hline \multicolumn{5}{|l|}{ Prosthesis, $n$ (\%) } \\
\hline Edwards S3 & $93(71)$ & $28(54.9)$ & 65 (81.3) & .2 \\
\hline $23 \mathrm{~mm}$ & $31(23.7)$ & 14 (27.5) & $17(21.3)$ & \\
\hline $26 \mathrm{~mm}$ & 43 (32.8) & 10 (19.6) & $33(41.3)$ & \\
\hline $29 \mathrm{~mm}$ & 19 (14.5) & $4(7.8)$ & $15(18.8)$ & \\
\hline Corevalve Evolut $\mathrm{R}$ & 35 (26.7) & $20(39.2)$ & $15(18.8)$ & .057 \\
\hline $23 \mathrm{~mm}$ & $3(2.3)$ & $2(3.9)$ & $1(1.3)$ & \\
\hline $26 \mathrm{~mm}$ & 19 (14.5) & $13(25.5)$ & $6(7.5)$ & \\
\hline $29 \mathrm{~mm}$ & $10(7.6)$ & $4(7.8)$ & $6(7.5)$ & \\
\hline $34 \mathrm{~mm}$ & $3(2.3)$ & $1(1.9)$ & $2(2.5)$ & \\
\hline Corevalve Evolut PRO & $3(2.3)$ & $3(5.9)$ & 0 & .06 \\
\hline $26 \mathrm{~mm}$ & $3(2.3)$ & $3(5.9)$ & & \\
\hline \multicolumn{5}{|l|}{ Catheter, $n(\%)$} \\
\hline Ascendra certitude delivery & $59(45.0)$ & - & $59(73.8)$ & 1 \\
\hline Commander delivery & $34(26.0)$ & $28(54.9)$ & $6(7.5)$ & .09 \\
\hline EnVeo Medtronic & $38(29.0)$ & $23(45.1)$ & $15(18.8)$ & .03 \\
\hline Predilatation, $n(\%)$ & 61 (46.6) & $23(45.1)$ & $38(47.5)$ & 1 \\
\hline Posdilatation, $n(\%)$ & $11(8.3)$ & $8(15.7)$ & $3(3.8)$ & .052 \\
\hline Radiation dose $\mathrm{cGy} \cdot \mathrm{cm}^{2}$, mean $\pm \mathrm{SD}$ & $3,087 \pm 2,528$ & $3,055 \pm 2089$ & $3,118 \pm 2,966$ & .89 \\
\hline Procedure length, mean \pm SD & $67.5 \pm 21.5$ & $64 \pm 18$ & $71 \pm 25$ & .051 \\
\hline Contrast amount $(\mathrm{ml})$, mean $\pm \mathrm{SD}$ & $71 \pm 24$ & $71 \pm 25$ & $71 \pm 23$ & .96 \\
\hline Radiation length (min), mean \pm SD & $10.5 \pm 5$ & $11 \pm 5$ & $10 \pm 5$ & .30 \\
\hline
\end{tabular}

Abbreviations: $\mathrm{cGy} \mathrm{cm}^{2}$, centigray/centimeter; ml, milliliter; SD, standard deviation.

due to heart failure $(p=.8)$. MVC were more frequent in the TF group $(p=.01)$, all requiring surgical revision. Transfusion was required in 13 patients $(9.9 \%)$ and $8,(61.5 \%)$ needed only 2 unit of red blood cells without difference between the two groups. Ischemic stroke occurred in $1(2.0 \%)$ patient in the TF group versus $2(2.5 \%)$ in the TC group ( 1 controlateral to the carotid access and 1 related to the procedure induced carotid occlusion with ipsilateral vertebral artery occlusion on CT scan), $p=.8$. 
TABLE 4 Primary and secondary endpoint in the study population, TF, and TC groups

\begin{tabular}{|c|c|c|c|c|}
\hline & Total population $(n=131)$ & TF group $(n=51)$ & TC group $(n=80)$ & $p$ \\
\hline Primary endpoint at 1-month & $18(13.8)$ & $10(19.6)$ & $8(10.0)$ & .1 \\
\hline Access failure, $n(\%)$ & $1(0.8)$ & $1(2.0)$ & $0(0)$ & .2 \\
\hline All-cause mortality, $n(\%)$ & $3(2.3)$ & $1(1.9)$ & $2(2.6)$ & .8 \\
\hline Major vascular complications, $n(\%)$ & $7(5.3)$ & $6(11.8)$ & $1(1.3)$ & .01 \\
\hline Major bleeding, $n(\%)$ & $13(9.9)$ & $7(13.7)$ & $6(7.5)$ & .2 \\
\hline Stroke, $n(\%)$ & $3(2.3)$ & $1(2.0)$ & $2(2.5)$ & .8 \\
\hline \multicolumn{5}{|l|}{ Secondary endpoints } \\
\hline ICU monitoring, $n(\%)$ & $108(82.4)$ & $28(54.9)$ & $80(100)$ & .04 \\
\hline ICU length of stay, mean \pm SD (days) & $2.4 \pm 1.4$ & $2.3 \pm 1.3$ & $2.4 \pm 1.4$ & .9 \\
\hline Pacemaker implantation, $n$ (\%) & $33(25.2)$ & $12(23.6)$ & $21(26.2)$ & .84 \\
\hline Minor VC, $n(\%)^{*}$ & $15(11.5)$ & $4(8)$ & $11(11.8)$ & .39 \\
\hline Mean aortic gradient, mean \pm SD & $9.5 \pm 3,7$ & $9.7 \pm 4.2$ & $9.3 \pm 3.2$ & .86 \\
\hline $\mathrm{AR}>$ grade 2 , mean $\pm \mathrm{SD}$ & $10(7.6)$ & $5(9.8)$ & $5(6.3)$ & .52 \\
\hline Hospitalization length of stay, mean \pm SD (days) & $6.9 \pm 3.8$ & $6.9 \pm 3.2$ & $6.8 \pm 4.3$ & .89 \\
\hline
\end{tabular}

Note: * according to the VARC-2criteria.

Abbreviations: AR, aortic regurgitation; ICU, intensive care unit; TF, complex transfemoral; TC, transcarotid; VC, vascular complications.

FIGURE 3 Primary endpoint: Proportion (\%) of major complications in TF and TC groups at 1-month postprocedure. MVC, major vascular complication; TF, transfemoral; TC, transcarotid. *The composite criteria of complications was reached if at least one of the major complications (mortality, stroke, bleeding, MVC and access failure) occurred [Color figure can be viewed at wileyonlinelibrary.com]

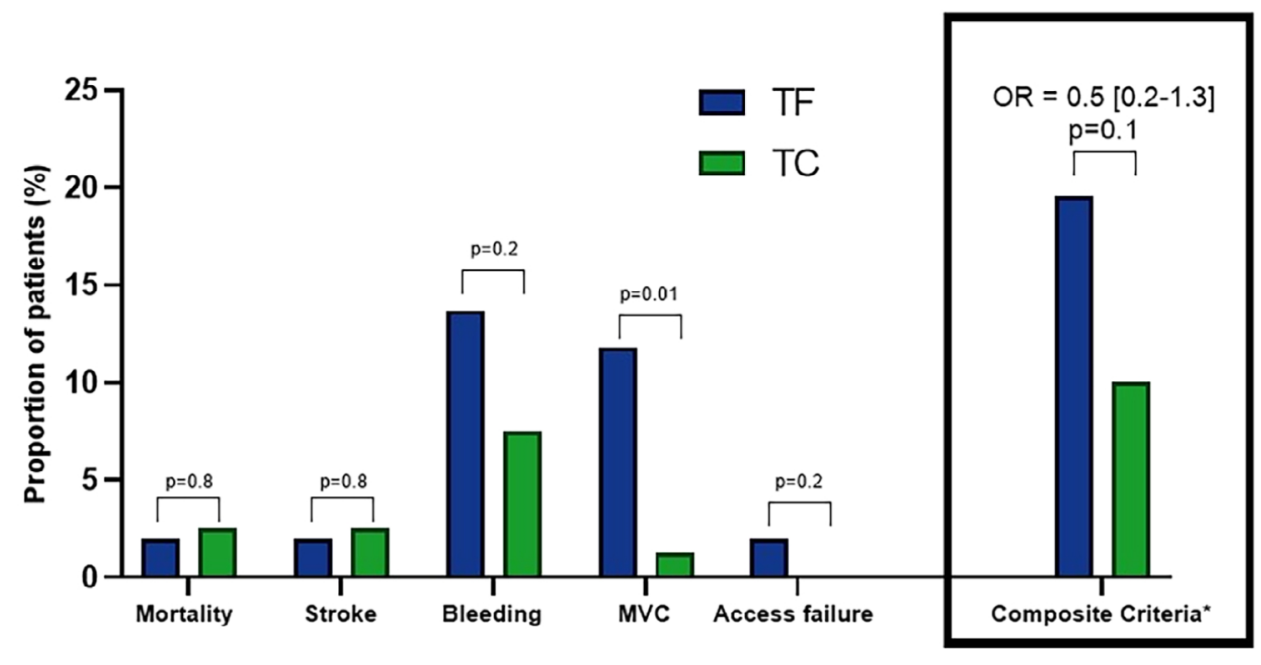

\subsection{Secondary endpoints}

According to our local monitoring protocol, all patients in the TC group and high risk patients $(n=28,54.9 \%)$ in the TF group were monitored in ICU during at least $24 \mathrm{hr}^{14}$ Non compressive carotid hematoma was the most common minor VC in the TC Group ( $n=8,10 \%)$. In the TF group, three patients had a femoral hematoma (5.9\%) and one patient had an arteriovenous fistula (1.9\%). Both groups had similar procedure duration, radiation dose, amount of contrast and hospitalization duration. Detailed data on secondary endpoints are presented Table 4.

\section{4 | DISCUSSION}

This study compared both success rate and safety of TC versus TF access in patients undergoing TAVR with complex aorta/iliofemoral anatomy with three main findings:
1. Complex iliofemoral or aortic anatomy was observed in $1 / 3$ of our TAVR cohort,

2. Despite higher risk profile of the patients in the TC group, we observed a two-fold reduction $(p=0.1)$ of the primary end point compared to the TF group with significantly less major VC and no access failure.

3. Similar radiation doses, contrast amount and hospitalization length were observed between the 2 strategies.

\section{1 | Complex vascular anatomy in TAVR and alternative}

Minimal iliofemoral artery diameter, presence of calcified iliofemoral arteries are predictive of complex TF access and correlated with increased risk of MVC during TAVR. ${ }^{2,4,15}$ In the Italian CoreValve 
registry, the presence of major access site complication was a strong (OR 8.47) independent predictor of 30-day mortality. ${ }^{16}$ In our study, complex iliofemoral and/or aortic anatomy was observed in $31 \%$ of our TAVR cohort as previously reported. ${ }^{2,17,18}$ Regarding TAVR access, the common carotid artery is superficial, making the dissection easy and a relative excess of length facilitates its surgical closure. ${ }^{19-21}$ The direct access from the sheath to the ascending aorta provides a good control of the valve positioning and avoids multiple manipulations in the aortic arch. TC approach should however be performed by an experienced vascular surgeon due to the presence of important local structures, such as the vagus nerve and the respiratory system. The subclavian and axillary arteries are of the elastic type while the femoral is of the muscular type. ${ }^{7}$ Those characteristics predispose this access to vascular complications such as ruptures or dissections. Apical or direct aortic approaches are more invasive and furthermore, these techniques are limited by contraindications such as significant respiratory failure in case of transapical, and porcelain aorta, as well as previous heart surgery, in case of transaortic approach. $^{22}$ TC approach was recently reported as safe and feasible in appropriately selected patients with a high rate of device success and similar outcomes to TF access. ${ }^{19-21}$

\section{2 | Favorable primary outcomes after TC approach}

In our study, despite higher risk profile of patients in the TC group, outcomes compared favorably with patients from the TF group. Moreover, the primary endpoint tended to be lower without reaching significance and MVC were significantly reduced in TC group ( $p=.02)$. While MVC remains one of the main complication of TF TAVR, our results argue to discuss a TC approach in patients with predictable challenging TF anatomy as recently pointed out in the FRANCE TAVI registry. ${ }^{3}$ TC group mortality rate in our study was low (2.6\%) and comparable to the results observed in the French transcarotid multicenter registry. ${ }^{20}$ Stroke is a major concern after TAVR and particularly for TC approach although randomized studies and registries did not find excess risk of neurologic events with this access. ${ }^{20-23}$ In our study, the stroke rate in the TC group was low (two patients) and only one of them could be attributed to the procedure induced carotid occlusion.

\section{3 | TAVR procedure course according to the strategy}

In our study, TC TAVR procedure was not associated with increased procedure duration, radiation dose or amount of contrast in comparison with TF approach as previously reported in registries. ${ }^{22,23}$ Postoperative care in TC access should include monitoring of signs of compressive hematoma (dysphonia, dysphagia, dyspnea) that may require emergency orotracheal intubation. However, no severe complication occurred in the TC patients in our study and the total hospitalization length was similar between both groups with similar data from others experienced teams. ${ }^{23,24}$

\subsection{Study limitations}

The first limitation of this study is inherent to its monocentric nature with a relative small number of patients. Considering the favorable tendency of the primary endpoint for the TC group, a statistical difference might be observed for the primary endpoint between the two groups with a larger population. The relatively short follow-up at 1 month could be considered as another limitation but, occurrence of adverse events seems unlikely to be related to the vascular approach of TAVR beyond 1 month. Finally, a higher rate of women in the TF group, may have induced a bias regarding incidence of VC.

\section{5 | Perspectives}

Regarding favorable outcomes, TC approach has become the secondline access in many centers but only proposed in case of impossible TF access. Regarding the results of our study, extension of TC approach as first alternative in complex TF access may be considered. However, randomized studies would be necessary to validate this strategy.

\section{5 | CONCLUSION}

Despite a higher patients' risk profile in our study, TC approach was associated with similar success rate and numerically lower rate of major clinical endpoints in comparison to TF approach in patients with complex aortofemoral anatomy. As TC access was associated with a significant lower rate of MVC without increasing of stroke, this approach should be considered as the first alternative in case of challenging vascular anatomy in patients undergoing TAVR.

\section{CONFLICT OF INTEREST}

Florence Leclercq received research grants from Edwards, Medtronic, Boehringer; consultant fees from Boehringer; and lecture fees from Astra Zeneca and Bayer.

Guillaume Cayla received research grants/consultant fees/lectures fees from Amgen, AstraZeneca, Abbott, Bayer, Biotronik, Bristol-Myers Squibb, Pfizer, Sanofi-Aventis.

Benoit Lattuca received research grants from ACTION Study group, Biotronik, Boston Scientific, Daiichi-Sankyo, Fédération Française de Cardiologie and Institute of CardioMetabolism and Nutrition; consultant fees from Daiichi-Sankyo and Eli Lilly; and lecture fees from AstraZeneca and Novartis.

Mariama Akodad received research grants from Edwards Lifescience and Medtronic.

Thomas Gandet received consultant fees from Medtronic. 
Romuald Choteau, Chloé Chamard, Youcef Lounes, Jean-Christophe Macia, Delphine Delseny have no conflicts of interest to declare.

\section{REFERENCES}

1. Baumgartner $H$, Falk V, Bax JJ, et al. ESC scientific document group. 2017 ESC/EACTS guidelines for the management of valvular heart disease. Eur Heart J. 2017;38:2739-2791.

2. Sinning J-M, Horack M, Grube E, et al. The impact of peripheral arterial disease on early outcome after transcatheter aortic valve implantation: results from the German Transcatheter aortic valve interventions registry. Am Heart J. 2012;164:102-110.

3. Beurtheret S, Karam N, Resseguier N, et al. Femoral versus nonfemoral peripheral access for Transcatheter aortic valve replacement. J Am Coll Cardiol. 2019;74:2728-2739.

4. Bauernschmitt R, Schreiber C, Bleiziffer S, et al. Transcatheter aortic valve implantation through the ascending aorta: an alternative option for no-access patients. Heart Surg Forum. 2009;12:63-64.

5. Ye J, Cheung A, Lichtenstein SV, et al. Transapical aortic valve implantation in humans. J Thorac Cardiovasc Surg. 2006;131:1194-1196.

6. Asgar AW, Mullen MJ, Delahunty N, et al. Transcatheter aortic valve intervention through the axillary artery for the treatment of severe aortic stenosis. J Thorac Cardiovasc Surg. 2009;137:773-775.

7. Petronio AS, De Carlo M, Giannini C, De Caro F, Bortolotti U. Subclavian TAVI: more than an alternative access route. Eurolntervention. 2013;9:S33-37.

8. Modine T, Lemesle G, Azzaoui R, Sudre A. Aortic valve implantation with the CoreValve ReValving system via left carotid artery access: first case report. J Thorac Cardiovasc Surg. 2010;140:928-929.

9. Watanabe M, Takahashi S, Yamaoka H, et al. Comparison of Transcarotid vs. Transfemoral Transcatheter aortic valve implantation. Circ J. 2018;82:2518-2522.

10. Wee IJY, Stonier T, Harrison M, Choong AMTL. Transcarotid transcatheter aortic valve implantation: a systematic review. J Cardiol. 2018;71:525-533.

11. Chaikof EL, Fillinger MF, Matsumura JS, et al. Identifying and grading factors that modify the outcome of endovascular aortic aneurysm repair. J Vasc Surg. 2002;35:1061-1066.

12. Du Cailar C, Gandet T, Du Cailar M, Albat B. A simple sheath removal after open trans-femoral catheterization procedure: the ZIP technique. Eur J Cardiothorac Surg. 2014;45:746-748.

13. Kappetein AP, Head SJ, Généreux P, et al. Valve academic research Consortium-2. Updated standardized endpoint definitions for transcatheter aortic valve implantation: the valve academic research Consortium-2 consensus document. J Thorac Cardiovasc Surg. 2013;145:6-23.

14. Leclercq F, lemmi A, Lattuca B, et al. Feasibility and safety of Transcatheter aortic valve implantation performed without intensive care unit admission. Am J Cardiol. 2016;118:99-106.

15. Toggweiler S, Gurvitch R, Leipsic J, et al. Percutaneous aortic valve replacement: vascular outcomes with a fully percutaneous procedure. J Am Coll Cardiol. 2012;59:113-118.

16. Tamburino C, Capodanno D, Ramondo A, et al. Incidence and predictors of early and late mortality after transcatheter aortic valve implantation in 663 patients with severe aortic stenosis. Circulation. 2011; 123:299-308.

17. Kinnel M, Faroux L, Villecourt A, et al. Abdominal aorta tortuosity on computed tomography identifies patients at risk of complications during transfemoral transcatheter aortic valve replacement. Arch Cardiovasc Dis. 2020;113:159-167.

18. Fusini L, Mirea O, Tamborini G, et al. Incidence and severity of atherosclerotic cardiovascular artery disease in patients undergoing TAVI. Int J Cardiovasc Imaging. 2015;31:975-985.

19. Mylotte D, Sudre A, Teiger E, et al. Transcarotid Transcatheter aortic valve replacement: feasibility and safety. JACC Cardiovasc Interv. 2016;9:472-480.

20. Overtchouk P, Folliguet T, Pinaud F, et al. Transcarotid approach for Transcatheter aortic valve replacement with the Sapien 3 prosthesis: a multicenter French registry. JACC Cardiovasc Interv. 2019;12:413-419.

21. Debry N, Trimech TR, Gandet T, et al. Transaxillary compared with transcarotid access for TAVR: a propensity-matched comparison from a French multicenter registry. Eurolntervention. 2020;16:842-849. https://doi.org/10.4244/EIJ-D-20-00117.

22. Chamandi C, Abi-Akar R, Rodés-Cabau J, et al. Transcarotid compared with other alternative access routes for Transcatheter aortic valve replacement. Circ Cardiovasc Interv. 2018;11:63-88.

23. Folliguet $\mathrm{T}$, Laurent $\mathrm{N}$, Bertram $\mathrm{M}$, et al. Transcarotid transcatheter aortic valve implantation: multicentre experience in France. Eur J Cardiothorac Surg. 2018;53:157-161.

24. Kallinikou Z, Berger A, Ruchat P, et al. Transcutaneous aortic valve implantation using the carotid artery access: feasibility and clinical outcomes. Arch Cardiovasc Dis. 2017;110:389-394. 